\title{
Seasonal nitrogen biogeochemical characteristics in porewater and sediment in the Wetland, Korea
}

\author{
HeE Sun MOON ${ }^{1,2}$, DONG-Hun KIM ${ }^{1}$, YoNG Hwa OH ${ }^{1}$, \\ Ji YeON HAN ${ }^{1,2}$, SEOLRAN OH ${ }^{1}$, SOO YOUNG $\mathrm{CHO}^{1}$ \\ 1 Groundwater Research Center, Korea Institute of Geoscience and Mineral Resources \\ (KIGAM), Daejeon, 34113, Republic of Korea, hmoon@kigam.re.kr \\ 2 Department of Mineral and Groundwater Resources, Korea University of Science and \\ Technology (UST), Daejeon, 34113, Republic of Korea
}

Wetlands have been considered as valuable ecosystems because they can serve as sinks for nutrients such as carbon and nitrogen, attenuating the release of nutrients into environment. The significant biological pathways of nitrogen removal in wetlands include nitrification and denitrification process. Recent climate change can affect the hydrologic conditions in wetland environments and consequently cause redox condition changes in nitrogen biogeochemical processes in wetland sediments. Therefore, it is more important to understand seasonally nitrogen biogeochemical characteristics in porewater and sediment. In this study, we monitored the seasonal nitrogen dynamic with sediment depths $(<1 \mathrm{~m})$ in two different sites $(\mathrm{PA}$ and $\mathrm{PB})$ in the wetland in Korea where is geographically located on the western part of Korea Peninsula (Gunsan-si, Jeonbuk province). The various nitrogen compounds (i.e., $\mathrm{TDN}, \mathrm{NO}_{3}^{-}$, $\mathrm{NO}_{2}^{-}$, and $\mathrm{NH}_{4}^{+}$) and dissolved organic carbon (DOC) concentration in pore water with depths were periodically monitored from year 2018 to 2019 and nitrogen-related functional genes in each sediment depths were also analyzed. The results showed that the significant seasonal variation in DOC concentration in porewater was observed which may be affected by temperature, plant growth and microbial activity. denitrification rate experiments were performed using the acetylene inhibition technique, and denitrification-related gene quantification was performed by $\mathrm{qPCR}$ analysis. As a result of potential denitrification rate, higher levels were observed at $0-10 \mathrm{~cm}$, with higher denitrification rates in December than in June. The qPCR analysis showed that the $\operatorname{nar} G$, nirS and nos $Z$ gene copy numbers were higher in December than in June, corresponding to an increase in potential denitrification rate in December. The different nitrogen dynamic with depth at three sites seem to be affected by different hydrological interaction and redox conditions at each sites. 